LA-UR- 046019

Approved for public release; distribution is unlimited.


Los Alamos National Laboratory, an affirmative action/equal opportunity employer, is operated by the University of California for the U.S. Department of Energy under contract W-7405-ENG-36. By acceptance of this article, the publisher recognizes that the U.S. Government retains a nonexclusive, royalty-free license to publish or reproduce the published form of this contribution, or to allow others to do so, for U.S. Government purposes. Los Alamos National Laboratory requests that the publisher identify this article as work performed under the auspices of the U.S. Department of Energy. Los Alamos National Laboratory strongly supports academic freedom and a researcher's right to publish; as an institution, however, the Laboratory does not endorse the viewpoint of a publication or guarantee its technical correctness. 


\title{
Ion irradiation of porous silicon: the role of surface states
}

\author{
L.G. Jacobsohn, B.L. Bennett, D.W. Cooke, R.E. Muenchausen and M. Nastasi
}

Los Alamos National Laboratory

Si wafer: $p$-type B-doped $3 \Omega$-cm

Etching: $0.33 \mathrm{~mA} / \mathrm{cm}^{2}$ for $6 \mathrm{~h}$ in

\section{1:1:2 $\mathrm{HF}: \mathrm{H}_{2} \mathrm{O}$ :ethanol solution}

$\mathrm{H}^{+} 35 \mathrm{kV}, \mathrm{He}^{+} 42 \mathrm{kV}, \mathrm{Ne}^{++} 109 \mathrm{kV}$

Range: $\sim 440 \mathrm{~nm}$ in c-Si

Doses: $1 \times 10^{9}-7 \times 10^{13}$ atoms $/ \mathrm{cm}^{2}$
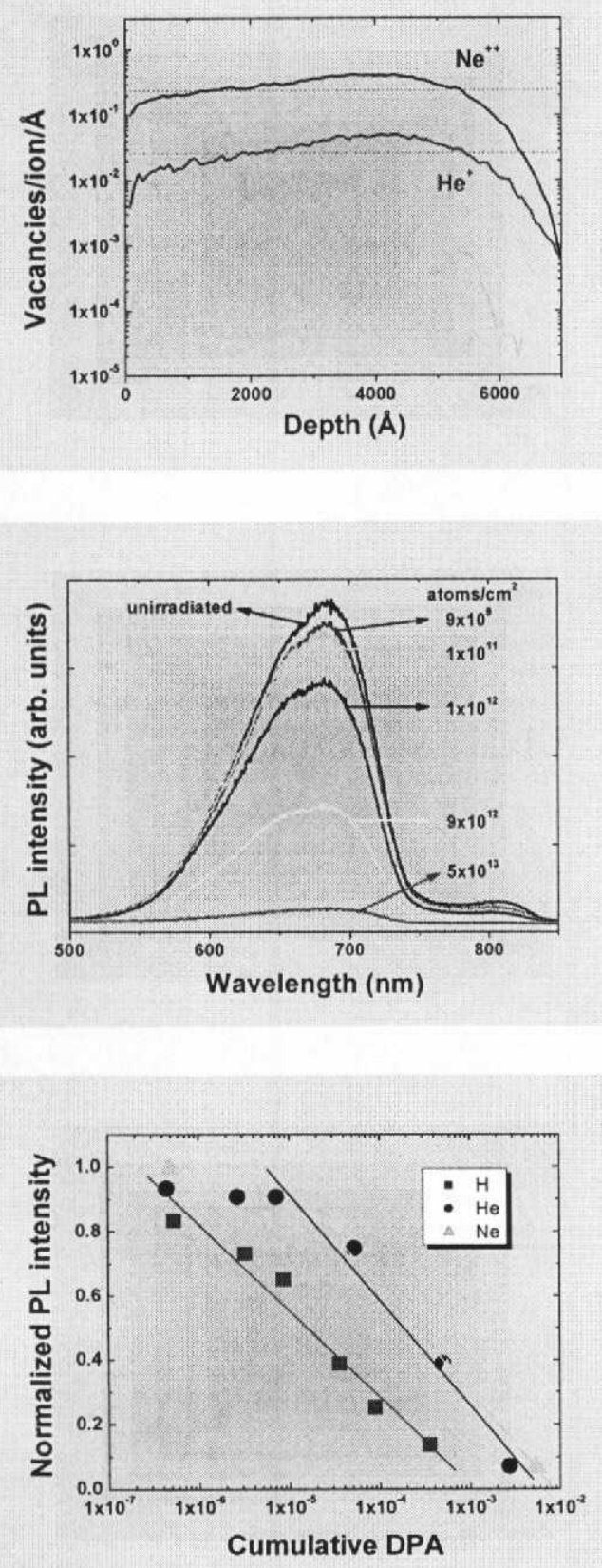
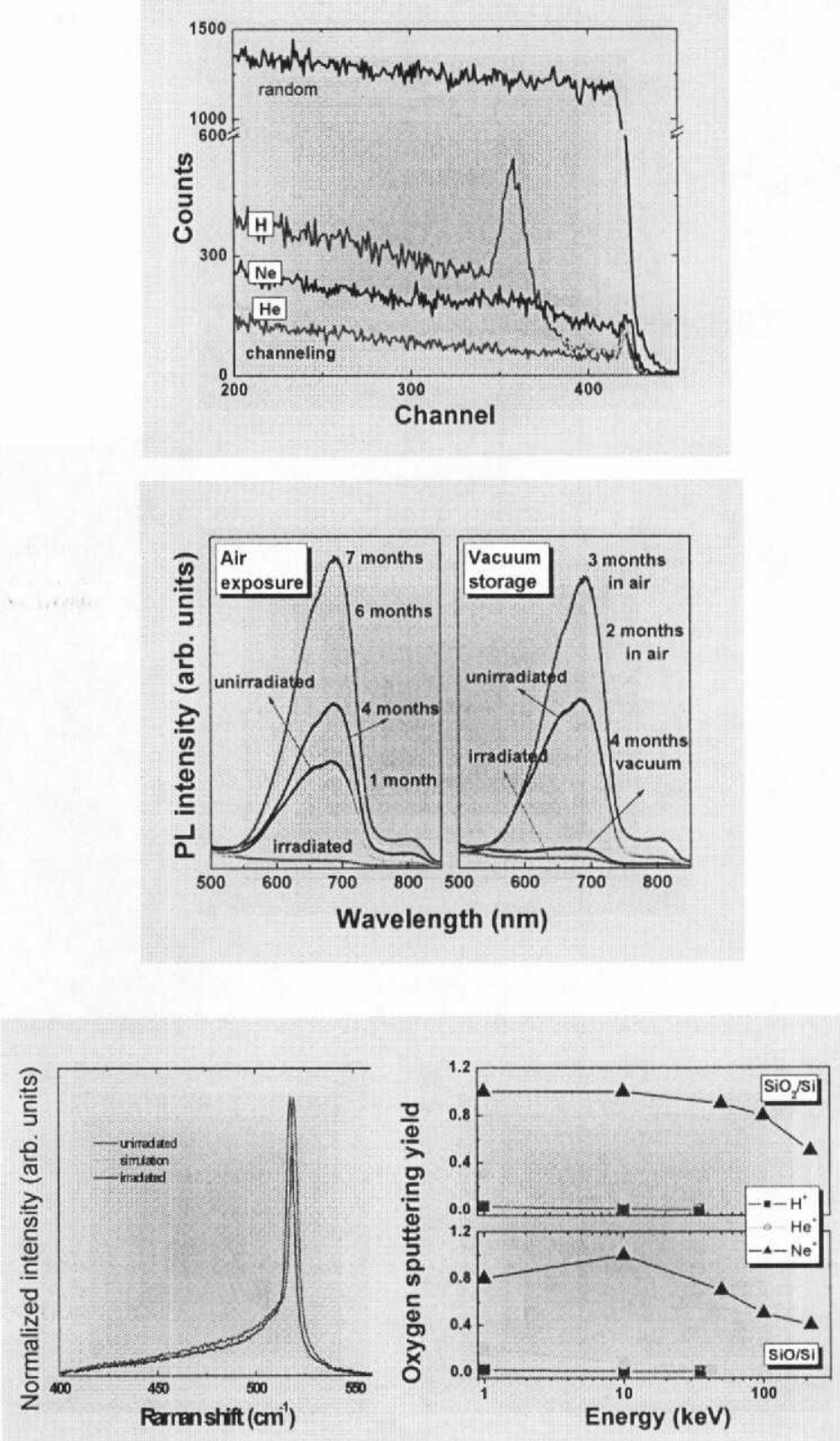

\section{Summary $\&$ conclusions:}

- Ion irradiation induces PL quenching from po-Si.

- Interaction of the implanted ions with defects generated during the irradiation process plays a major role in the $\mathrm{PL}$ quenching mechanism.

- Quenching was associated with the creation of nonradiative states within the gap.

- Exposition to air and consequently the oxidation of the surface is shown to enhance PL emission efficiency. 